\title{
Виктор МИРОНЕНКО
}

\section{«УКРАИНСКИЙ ТРАНЗИТ БОЛЬШОЙ ЭЛЕКТОРАЛЬНЫЙ ЦИКЛ: ШАНС ИЛИ ВЫЗОВ?}

\begin{abstract}
Аннотация. Украина находится в состоянии трансформации, в поиске адекватной общественно-политической модели. Она переживает второй трансформационный кризис. Его глубину и пути выхода из него показал закончившийся большой электоральный иикл (БЭЦ) президентские, парламентские и местные выборы в 2019-2020 г2. Имеющиеся степени свободы, предпочтение, отдаваемое гражданами Украины правовым способам ремения возникающих политических проблем перед любыми другими, проявившееся в само́м факте этих выборов и в том как они проходили, выделяют и это общество, и это новое независимое государство на общем несколько неопределённом и тусклом фоне т.н. «постсоветского пространства». Всё это делает Украину и происходящие в ней процессы лакмусовой бумажкой, тестом на способность и готовность к решительной демократизации и согласованной модернизаџии. Для Украины большой электоральный ичикл, то, как он завериился - это и вызов, и шанс. Как она на него ответит и им воспользуется в свете этих важных политических событий? На этот вопрос делается попытка ответить в предлагаемой статье.
\end{abstract}

Ключевье слова: Украина, второй трансформачионный кризис, выборы, электоральная револючия, украинский транзит, четвёртая украинская республика, постсоветское пространство, согласованная модернизация.

Предлагаемый текст завершает цикл статей, посвящённых Украине, и отражает точку зрения автора на происходящие в ней процессы ${ }^{1}$. В поиске адекватной общественно-политической модели, самая молодая из больших стран Европы переживает трансформационный кризис. Указателем пути выхода из него и одновре́менно вызовом стал большой электоральный цикл - серия общенациональных выборов: президентских и парламентских в 2019 г, местных в 2020 г.

\section{Электоральная революция}

«Большой электоральный цикл» представляет собой политический процесс, начавшийся в 2019 г. с выборов президента Украины, продолжившийся на внеочередных парламент-

(C) Мироненко Виктор Иванович - кандидат исторических наук, ведущий научный сотрудник, руководитель Центра украинских исследований Отдела страновых исследований ИЕ РАН. Адрес: 125009 , Россия, Москва, ул. Моховая, д. 11, стр. 3. E-mail: victor@mironenko.org.

Статья поступила в редакциию: 19.12.2020.

${ }_{1}^{1}$ Мироненко В.И. «Украинский транзит»: попытка анализа и прогноза // Научно-аналитический вестник ИЕ РАН. 2020. №3. С. 95-100; Мироненко В.И. «Украинский транзит»-2 // Научно-аналитический вестник ИЕ РАН. 2019. №4 С. 21-26; Мироненко В.И. «Украинский транзит»-3. О некоторых уроках украинских «революций» // Научно-аналитический вестник ИЕ РАН. 2020. №1 С. 94-99; Мироненко В.И. «Украинский транзит»-4. Испытание пандемией // Научно-аналитический вестник ИЕ РАН. 2020. №3. С. 95-100; Мироненко В.И. «Украинский транзит»-5. Местные выборы как тест для Украины // Научно-аналитический вестник ИЕ РАН. 2020. №4. С. 3842; Мироненко В.И. «Украинский транзит»-6. Украина - не Беларусь // Научно-аналитический вестник ИЕ PAH. 2020. №5. C. 84-91. 
ских выборах и завершившийся местными выборами в 2020 г.

Начался он несколько ранее обозначенного временно́го интервала в 2018 г. со своего рода политической «pole-position» ${ }^{1}-$ позиционирования кандидатов ${ }^{2}$. Всё, что произошло потом, с одной стороны, было продолжением предыдущих выборных циклов (с двумя катарсисами $^{3}$ - в 2004 и 2014 гг.). С другой - составившие его события объективно могли и, на наш взгляд, должны были дать старт новому этапу «украинского транзита», уточнить его цели и придать ему ускорение. Вполне возможно, что радикальная смена лиц в украинской политике приведёт к смене её типа, к её гуманизации, к перезагрузке всей политической системы.

Всё произошедшее, с одной стороны, положило конец известной политико-правовой неопределённости, наступившей после трагических событий зимы 2013-2014 гг. Украина возвратилась в конституционно-правовое поле, к установившейся в ней ранее традиции решать возникающие проблемы политическими и юридическими средствами. С другой стороны, для обозначения происходящего был использован оксюморон «электоральная революция» ${ }^{4}$. Термин «революция» не бесспорен, но в данном случае вполне уместен. Трудно найти другое определение для того «идеального шторма», который буквально смёл с политической сцены почти всю старую элиту.

Украинское общество извлекло уроки из трагических событий зимы 2014 г., повзрослело в испытаниях и более адекватно, чем украинский политикум, реагирует на вызовы. Революционная, по существу, ситуация, усугублённая вооружённым выступлением сепаратистов, была разрешена с использованием конституционных процедур, без чрезвычайщины.

У президентских выборов была и ещё одна особенность, на которую немногие обратили внимание. Предыдущие были внеочередными и во многом чрезвычайными. Нужно было спасать Третью украинскую республику, а вместе с ней и надежды, связанные с обретением государственного суверенитета, от эрозии, вызванной политикой двух предыдущих администраций ${ }^{5}$.

Молодое украинское государство не выработало иммунитета к распространённой политической болезни - популизму. Но популизм на Украине весьма специфичен. Необходимость прислушиваться к общественному мнению, боязнь потерять поддержку в мире помогла относительно безболезненно пройти опаснейший рубеж - смену политических поколений. Как иначе объяснить то, что новичку в политике, не имевшему ни сильной команды, ни больших финансовых ресурсов, В. Зеленскому, удалось обойти в первом туре президентских выборов политических «тяжеловесов», а во втором - с большим отрывом действовавшего президента П. Порошенко.

Неожиданностью были и результаты внеочередных парламентских выборов. Созданная $a d$ hoc из мало кому известных ранее в публичной политике лиц, партия в клочья порвала «политическое облачение» Третьей республики. Парламент обновился на 80\%, помолодев на

\footnotetext{
${ }^{1}$ Поул-позиция (англ. pole-position) - наиболее выгодная позиция автомобиля, занимаемая гонщиком по итогам квалификации.

${ }^{2}$ Об этом подробнее см.: Мироненко В.И. Заметки с 15-й встречи «Ялтинской европейской стратегии» // Европейская аналитика 2018. М.; СПб: Нестор-История, 2018. С. 159-167.

${ }^{3}$ Катарсис - процесс высвобождения эмоций, разрешения внутренних конфликтов и нравственного возвышения, возникающий в ходе самовыражения.

${ }^{4}$ См. напр.: Моцок В. «Електоральна революція» в американській політиці сприяння демократії для Східної Європи // Історико-політичні проблеми сучасного світу: зб. наук. ст. Т. 25-26. Чернівці: Рута, 2013; Касьянов Г. Первая революция. Как изменится Украина после парламентских выборов. Московский центр Карнеги. 26.07. 2019. URL: https://carnegie.ru/commentary/79571 (дата обращения 09.12.2020).

${ }^{5}$ Куликов Ю. Как экономическая политика Януковича чуть не угробила Украину. УНИAH. 17.02.2020. URL: https://www.unian.net/economics/finance/10874345-kak-ekonomicheskaya-politika-yanukovicha-chut-ne-ugrobilaukrainu.html? (дата обращения 09.12.2020).
} 
10 лет. Выборы показали, что доверие к существующему политическому режиму необратимо подорвано, а механизмы его функционирования дискредитированы и деформированы настолько, что вряд ли могут быть восстановлены. Задача радикального реформирования системы государственного управления из актуальной превратилась в неотложную.

\section{От парламентских выборов к местным}

Можно было ожидать, что победители, чтобы закрепить политический успех попытаются максимально приблизить заключительную фазу БЭЦ, ускорить проведение местных выборов ${ }^{1}$. Но верх взяло понимание того, что лучше, во-первых, не нарушать установленные законом сроки их проведения, а, во-вторых, взять паузу и осмотреться.

Местные выборы, помимо прочего, давали возможность ускорить, а, может быть, и завершить децентрализацию. Сомнений в её необходимости уже не оставалось. Существующая система с беспомощным местным самоуправлением стала камнем преткновения, а «альтернатива» регулярных «майданов» уже никого не привлекала.

БЭЦ давал шанс выбраться из наезженной политической колеи. Никогда ещё за всю новейшую историю Украины ни один человек, ни одна политическая партия не получали столь широких и консолидированных властных полномочий. В. Зеленский заявил: «Есть уникальный шанс провести все необходимые реформы... У нас для этого есть всё: есть политическая воля президента, есть большинство в Верховной Раде, есть очень настроенные работать правительство и премьер-министр» ${ }^{2}$.

Готовы ли к этому общество и политическая элита и должен был показать третий заключительный этап украинского политического марафона - выборы в органы местного самоуправления. Он мог либо закрепить наметившуюся тенденцию, либо, «вернуть Украину в состояние политической неопределённости» ${ }^{3}$.

Скажем сразу, что ясного ответа на этот вопрос они не дали. Тому было несколько причин. Во-первых, они «стали выборами местных органов власти в масштабах "Малой Украины”»", в 119 районах из 136. Выборы не состоялись в Крыму, Горловском, Донецком, Алчевском районах Донецкой области, Довжанском, Луганском, Ровеньковском и Кальмиусском районах Луганской области. Во-вторых, они проходили в ожидании назревших радикальных реформ, на неблагоприятном общем политическом фоне. Вместо немедленной перезагрузки системы новая администрация предпочла выжидание активным действиям и занялась перезагрузкой команды. За год сменились глава президентского офиса, генеральный прокурор, Кабинет Министров и его глава, часть руководителей областных администраций. Экономические провалы, усугублённые коррупцией и пандемией COVID-19, невозможность закончить войну, к чему мы ещё вернемся, многих разочаровали. Низкой оказалась явка $-36,88 \%{ }^{5}$. В выборах участвовали 40 из 349 зарегистрированных политических партий ${ }^{6}$.

\footnotetext{
${ }^{1}$ См.: Мироненко В.И. «Украинский транзит»-5. Местные выборы, как тест для Украины // Научно-аналитический вестник ИЕ РАН. 2020. №4. С. 38-42.

УНИАН 09.03.2019. URL: https://www.unian.net/economics/other/10671858-novaya-ze-ekonomika-prioritetnyezadachi-i-sroki-realizacii.html (дата обращения 08.12.2020).

${ }^{3}$ Иларионов А. Интервью. Сайт «Гордон». 22.10.2019. URL: https://gordonua.com/blogs/illarionov/vernuv-ordlo-vsostav-ukrainy-okruzhenie-zelenskogo-rasschityvaet-na-sleduyushchih-vyborah-poluchit-ottuda-ne-menee-2-mlngolosov-1364451.html (дата обращения 08.12.2020).

${ }_{4}^{4}$ Местные выборы-2020: другие итоги. Strategic Group Sofia. 2019, ноябрь. URL: http://sg-sofia.com.ua/mestijevibori-2020-drugiye-itogi (дата обращения 10.12.2020).

5 Центральна виборча комісія України. РБК. 25.12.2020. URL: https://vybory.rbc.ua/ukr/2020/obyavlena-vkaizbirateley-mestnyh-vyborah-1603636486.html (дата обращения 10.12.2020).

${ }^{6}$ Відомості щодо зареєстрованих у встановленому законом порядку політичних партій станом на 01 січня 2020 року. Міністерство юстиції України. URL: https://minjust.gov.ua/m/4561 (дата обращения 14.12.2020).
}

Научно-аналитический вестник ИЕ РАН, 2020, №6 
Предварительные итоги выглядят так':

\begin{tabular}{|l|c|c|c|}
\hline \multicolumn{1}{|c|}{ Партия } & Избрано депутатов & \% голосов & к 2015 г. \\
\hline Слуга народа & 305 & 17,3 & - \\
\hline Европейская солидарность & 283 & 15,9 & $-7,89$ \\
\hline Оппозиционная платформа «За жизнь» & 230 & 12,92 & - \\
\hline ВО «Родина» («Батьківщина») & 192 & 10,79 & $-4,32$ \\
\hline За Будущее & 183 & 10,28 & - \\
\hline ВО «Свобода» & 50 & 2,81 & $-4,06$ \\
\hline Блок Кернеса & 46 & 2,58 & - \\
\hline Наш край & 43 & 2,42 & $-1,76$ \\
\hline Украинская стратегия Гройсмана & 40 & 2,25 & - \\
\hline Предложение («Пропозиція») & 35 & 1,97 & - \\
\hline Радикальная партия О. Ляшко & 27 & 1,52 & $-5,4$ \\
\hline Доверие («Довіра») & 22 & 1,24 & - \\
\hline Родной дом & 19 & 1,07 & - \\
\hline
\end{tabular}

Составлено автором по данным ЦИК и СМИ ${ }^{2}$.

\section{Особенности местных выборов}

Остановимся подробнее на особенностях третьей, последней части БЭЦ.

Поскольку такие животрепещущие проблемы, как война, коррупция, безработица, экономический спад, уровень и качество жизни находятся вне местной компетенции, местные партийные проекты и региональные элиты получили очевидное преимущество и заявили о своём намерении участвовать в обустройстве жизненного пространства.

По-прежнему самыми активными были пожилые избиратели. 56\% из пришедших на выборы, были старше 50 лет. Выборы показали растущее в самостоятельной, экономически и политически деятельной части украинского общества разочарование в политикуме, даже обновлённом. Избиратели в возрасте 18-39 лет составили лишь 28\% проголосовавших, хотя в общей структуре украинского электората их $38 \%$. Пессимисты заговорили о «тихой контрреволюции». Накануне выборов лидеры находящихся в оппозиции партий открыто угрожали реваншем, но он не состоялся. Его элементами можно считать разве что отмеченное частью украинского общества неприятие новых «майданов», как средства разрешения политических споров, с одной стороны, и откладывания решения назревших проблем, с другой. Выбор людей был мотивирован потерей политического доверия и частичной утратой надежды. Они выбирали местную власть, надеясь с нею как-то разумно обустроить хотя бы своё «ближнее» жизненное пространство.

БЭЦ и особенно местные выборы показали, что новое районирование привело к реструктуризации самоуправления. Многие из новообразованных районов могут претендовать на статус «микро-регионов». Некоторые области состоят из 3-5 районов. Они получили своё представительство, что потребует от префектов, как представителей государственной власти на местах, искать с ним хотя бы минимального взаимопонимания. Вследствие этого появляется надежда на то, что новая политическая модель будет создаваться и сверху, и снизу.

Президент В. Зеленский и партия «Слуга народа» понесли серьёзные имиджевые потери, но сохранили за собой реноме новой политической силы, способной при определённых условиях реализовать очевидный запрос на смену политического устройства украинской республики.

\footnotetext{
${ }_{2}^{1}$ На момент написания статьи окончательные официальные итоги оглашены не были.

2 См.: ЦВК назвала партії, які взяли найбільше мандатів на місцевих виборах. РБК. 17.11.2020. URL: https:// vybory.rbc.ua/ukr/2020/tsik-nazval-partii-kotorye-vzyali-bolshe-1605726497.html (дата обращения 20.11.2020).
}

Научно-аналитический вестник ИЕ РАН, 2020, №6 
Новое качество местной власти вполне может стать основой для изменения политической архитектуры на Украине. Во избежание политической деструкции и потери управления необходимо минимизировать несовпадение позиций местной и центральной власти, проявившееся, например, в неприятии режима lockdown в Черкассах и Тернополе. Разногласия разной силы ожидаются в первую очередь в таких вопросах, как финансирование социальной инфраструктуры, распоряжение природными ресурсами, в частности, землёй, которая находится вне населённого пункта, а также выделение территорий под разработку природных ископаемых, распоряжение налогами, которые собираются на местах.

Но в целом экономическая консолидация в процессе укрупнения районов открывает для них и для экономики страны новые возможности. Объединение бюджетов развития даже в формате ОТГ и природных ресурсов, чему способствует передача государственных с/х земель в муниципальную собственность, создают предпосылки для развития местной экономики.

Вследствие БЭЦ общенациональная повестка дня неизбежно будет потеснена местной. Далеко не везде национальные лидеры симпатий избирателей оказываются таковыми и в регионах. Так, например, в Киеве, лидерами общественных симпатий являются «Европейская солидарность», партия «Удар»; в Харькове - «Блок Кернеса - Успешный Харьков» и «Оппозиционный блок «За жизнь»; во Львовской области - «Европейская солидарность», «Голос», «Самопомощь» и ВО «Свобода»; в Донецкой и Луганской областях ${ }^{1}-$ «Оппозиционная платформа» ${ }^{2}$. В целом в последние годы отмечается рост авторитета местных властей. Есть мнение, что людей будет больше заботить защищённость и обеспеченность в своём регионе, городе, в своей «малой родине» ${ }^{3}$.

БЭЦ оживил общественно-политическую жизнь на местах ${ }^{4}$. Вряд ли стоит сильно опасаться того, что Я. Мунк обозначил оксюмороном - «недемократический либерализм» ${ }^{5}$, имея в виду, что нет диктатуры более политически бесплодной, чем диктатура толпы. Но, в отличие от персоналистской диктатуры, массовые протестные выступления несут в себе ген альтернативности. «Электоральная революция» на Украине после двух «цветных» в 2004 и 2014 гг. свидетельствует о том, что процесс демократизации здесь развивается несколько иначе, чем в других европейских странах, примерно так, как это представлял себе С. Хантингтон 6 .

БЭЦ показал, что Украина вступает во «второй трансформационный кризис»7. Поднимающаяся волна новых трансформаций в Восточной Европе вовлечёт в политику более широкие социальные слои, сгенерирует новое поколение активистов, поставит в повестку дня радикальную перезагрузку сформировавшихся здесь гибридных политических систем.

Очевидный кризис традиционной формы национального государства, известный хаос в международных отношениях, говорят о том, что вопрос как жить дальше повис в воздухе и превращается в глобальную угрозу. Приобретённый Украиной в этом БЭЦ опыт, может оказаться поучительным и полезным.

\footnotetext{
${ }^{1}$ На контролируемых украинской властью частях их территории, за исключением 10 объединенных территориальных общин (громад) в Донецкой области и 8 - в Луганской области, где проведение выборов пока что признано невозможным.

${ }^{2}$ Кміть Ю. Місцеві вибори - 2020. Перспективи, прогнози, національний та регіональний вимір. Львівський портал, 8 липня 2020. URL: https://portal.lviv.ua/news/2020/07/08/mistsevi-vybory-2020-perspektyvy-prohnozynatsionalnyj-ta-rehionalnyj-vymir (дата обращения 10.08.2020).

3 Ермолаев А. Украина: испытание ультраглобализмом. Strategic Group Sofia. 2020, апрель. URL: http://sgsofia.com.ua/ukraina-ispitaniye-ultraglobalizmom-yermolaiev (дата обращения 16.04.2020).

${ }^{4}$ Там же.

${ }_{6}^{5}$ Mounk Y. Illiberal Democracy ore Undemocratic Liberalism. Project Syndicate. June 9, 2016.

${ }^{6}$ Huntington S. How Countries Democratize // Political Science Quarterly. 1991. Vol. 106. №4. P. 579-616.

${ }^{7}$ Ермолаев А. Украина: испытание ультраглобализмом ...
} 


\section{Список литературы}

Ермолаев А. Второй трансформационный кризис. Strategic Group Sofia. август 2019. URL: http://project705127.tilda.ws/vtoroj-transformazionij-krizis? (дата обращения 06.08.2020).

Ермолаев А., Щербина В., Емец В., Ермолаев Д. (2020). Местные выборы в Украине: другие итоги (социологическая и политическая аналитика). Стратегическая группа София. Киев.

Касьянов Г. Первая революция. Как изменится Украина после парламентских выборов. Московский центр Карнеги. 26.07.2019. URL: https://carnegie.ru/commentary/79571 (дата обращения 09.12.2020).

Кміть Ю. Місцеві вибори - 2020. Перспективи, прогнози, національний та регіональний вимір. Львівський портал. 08.07.2020. URL: https:/portal.lviv.ua/news/2020/07/08/mistsevi-vybo ry-2020-perspektyvy-prohnozy-natsionalnyj-ta-rehionalnyj-vymir (дата обращения 10.08.2020).

Куликов Ю. Как экономическая политика Януковича чуть не угробила Украину. УНИАН. 17.02.2020. URL: https://www.unian.net/economics/finance/10874345-kak-ekonomicheskayapolitika-yanukovicha-chut-ne-ugrobila-ukrainu.html? (дата обращения 09.12.2020).

Моцок В. «Електоральна революція» в американській політиці спряння демократії для Східної Свропи // Історико-політичні проблеми сучасного світу: зб. наук. ст. Т. 25-26. Чернівці: Рута, 2013. С. 97-102.

\section{References}

Ermolaev, A. Vtoroj transformacionnyj krizis [The second transformational crisis]. Strategic Group Sofia. August 2019. Available at: http://project705127.tilda.ws/vtoroj-transformazionijkrizis? (accessed 06.08.2020). (In Russian).

Ermolaev, A., Shherbina, V., Emec, V., Ermolaev, D. (2020). Mestnye vybory v Ukraine: drugie itogi (sociologicheskaja i politicheskaja analitika) [Local elections in Ukraine: other results (sociological and political analytics)]. Strategic Group Sofia. Kiev. (In Russian).

Kas'janov, G. Pervaja revoljucija. Kak izmenitsja Ukraina posle parlamentskih vyborov [First revolution. How Ukraine will change after the parliamentary elections]. Moskovskiı centr Karnegi [Carnegie Moscow Center]. 26.07.2019. Available at: https://carnegie.ru/commentary/79571 (accessed 09.12.2020). (In Russian).

Kmit', Ju. Miscevi vibori - 2020. Perspektivi, prognozi, nacional'nij ta regional-nij vimir [Prospects, forecasts, national and regional vimir]. L'vivs'kij portal [Lviv portal]. 08.07.2020. Available at: https://portal.lviv.ua/news/2020/07/08/mistsevi-vybory-2020-perspektyvy-prohnozy-natsionalny j-ta-rehionalnyj-vymir (accessed 10.08.2020). (In Ukrainian).

Kulikov, Ju. Kak jekonomicheskaja politika Janukovicha chut' ne ugrobila Ukrainu [How Yanukovych's economic policy nearly ruined Ukraine]. UNIAN. 17.02.2020. Available at: https:// www.unian.net/economics/finance/10874345-kak-ekonomicheskaya-politika-yanukovicha-chut-neugrobila-ukrainu.html? (accessed 09.12.2020). (In Russian).

Mocok, V. (2013). «Elektoral'na revoljucija» v amerikans'kij politici sprjannja demokratiï dlja Shidnoï Cvropi [«Electoral Revolution» in American Politics Spreading Democracy for Eastern Europe]. Istoriko-politichni problemi suchasnogo svitu [Historical and Political Problems of Contemporary World]. Vol. 25-26. Chernivci: Ruta. P. 97-102. (In Ukrainian).

\section{«Ukrainian Transit»-7. Large Electoral Cycle: a Chance or a Challenge?}

Author. Victor Mironenko, Candidate of Sciences (History), Chief of the Centre for Ukrainian Studies of the Department of Countries Studies, Institute of Europe, Russian Academy of Sciences. Address: 11-3, Mokhovaya str., Moscow, Russia, 125009. E-mail: victor@mironenko.org. 


\begin{abstract}
Ukraine is in a state of transformation, in search of an adequate social and political model. It's going through a second transformational crisis. The depth and the way out of it showed the completed large electoral cycle - presidential, parliamentary, and local elections in 2019-2020. The degree of freedom available, the preference given by Ukrainian citizens to legal means of solving emerging political problems over any other, as demonstrated by the very fact of these elections and the manner in which they were conducted, are singled out this society and this new independent state on a common somewhat uncertain and dim background of the «post-Soviet space». All this makes Ukraine and its processes a litmus test of the ability and readiness of Ukraine and other newly independent States to resolutely democratize and modernize themselves in a coordinated manner. For Ukraine, a large electoral cycle, the way it ended, is both a challenge and a chance. How will she respond to and use it in the light of these important political developments? The proposed article attempts to answer this question.

Key words: Ukraine, second transformational crisis, elections, «electoral revolution», Ukrainian transit, fourth Ukrainian republic, «post-Soviet space, agreed modernization.
\end{abstract}

DOI: http://dx.doi.org/10.15211/vestnikieran620208086 